\title{
EXTENSIBILITY OF THE PULMONARY TRUNK IN HEART DISEASE
}

\author{
BY \\ PETER HARRIS, DONALD HEATH, AND ANDREAS APOSTOLOPOULOS \\ From the Departments of Medicine and Pathology, University of Birmingham, Queen Elizabeth Hospital, \\ Birmingham 15 \\ Received October 28, 1964
}

The development of pulmonary hypertension is associated with an increased thickness of the wall of the pulmonary trunk. In those patients with large post-tricuspid shunts (e.g. ventricular septal defect or patent ductus arteriosus) in whom pulmonary hypertension has existed from birth, the elastic tissue in the pulmonary trunk preserves its fœtal appearance which is similar to that of the aorta (Heath et al., 1959). When the pulmonary hypertension has arisen later in life, the elastic tissue has a normal adult appearance (Heath et al., 1959). The wall of the pulmonary trunk in patients with Fallot's tetralogy is abnormally thin and the elastic tissue also appears abnormal (Heath et al., 1959). It seems likely that such changes in the structure of the vessel would be accompanied by changes in its physical characteristics. The extensibility of the normal human pulmonary trunk has been discussed in the preceding paper (Harris, Heath, and Apostolopoulos, 1965). In the present study, the extensibility of abnormal vessels has been examined and compared with what would normally be expected.

\section{METHODS}

The extensibility of circumferential strips of pulmonary trunk removed after death has been measured by the method previously described (Harris et al., 1965). The strips were subjected to a series of standard extensile loads, and the degree of extension was measured. The extensile force has been expressed in terms of dynes per mm. ${ }^{2}$ cross-sectional area. The histological techniques were the same as those used in the previous study.

Five groups of patients have been investigated: 9 had chronic rheumatic disease of the mitral valve; 6 had Fallot's tetralogy; 2 had idiopathic pulmonary hypertension; 2 had a ventricular septal defect; and 2 had an atrial septal defect of the secundum type. Details of these subjects are given in the Table.

\section{RESULTS}

The relation between length and extensile force in the normal pulmonary trunk is a curved one, the nature of which is dependent on age. In order to predict the degree of extension which would normally be expected for a particular extensile force in a subject of a particular age, an empirical formula has been derived (Harris et al., 1965).

$$
\Delta l=0.24 F^{0.62} e^{-0.00012 F^{0.49}} \text { xage }
$$

where $\Delta 1$ is the percentage extension and $F$ is the extensile force (dynes/mm. ${ }^{2}$ ). The regression equation for predicted $(y)$ on observed $(x)$ values for the percentage extension is as follows:

$$
y=0.52+0.9835 x
$$

and the standard error of the estimate is 4.91 . 
In view of the curved nature of the relation under consideration, and its dependence on age, the above formula has been used to examine whether the observations made on patients with abnormalities of the pulmonary circulation are different from what would normally be expected.

Disease of the Mitral Valve. Figure 1 shows the relation between the extensile force per unit cross-sectional area and the degree of extension observed in this group of subjects. It was not possible to say, simply from an inspection of such a diagram, whether the observations were normal or not. In Fig. 2 the observed degree of extension is plotted against that which would be predicted from equation (1). The regression line for the normal relation is shown together with lines at a distance of twice the standard error. The observations from the subjects with mitral

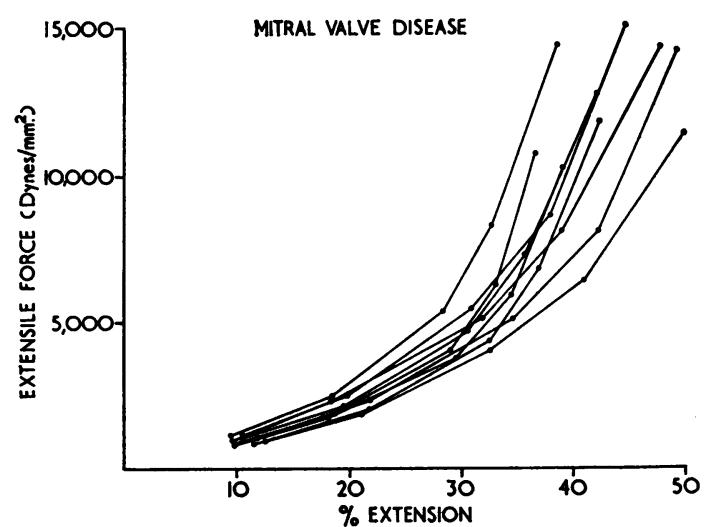

FIG. 1.-The extensibility of the tissue of the pulmonary trunk in subjects with disease of the mitral valve.

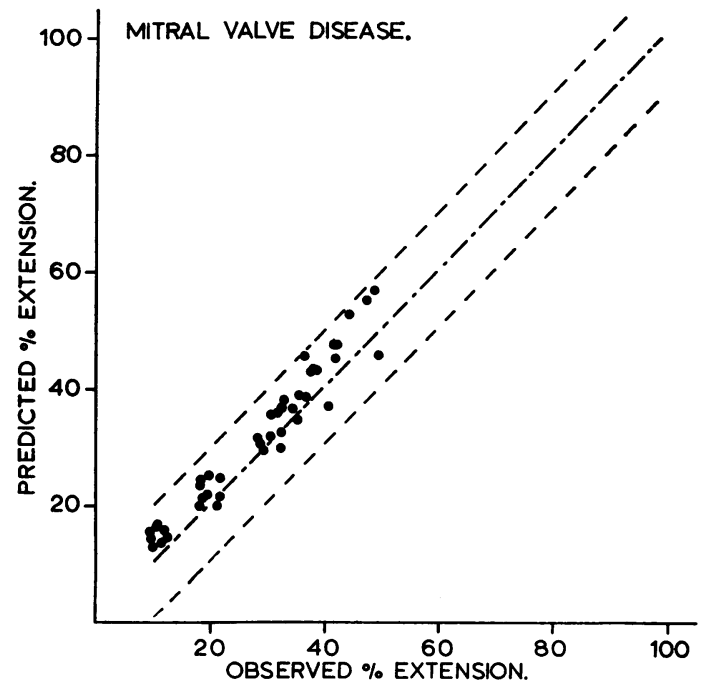

FIG. 2.-The relation between the observed degree of extension and that predicted from equation (1) in subjects with disease of the mitral valve. The "normal" regression line of equation (2) is shown, together with lines at a distance of twice the standard error of the estimate. disease lay within these limits.

The elastic tissue of the pulmonary trunk was of "adult pulmonary configuration" (Heath et al., 1959) which is found in normal adults and in patients with acquired pulmonary hypertension. There was an open network of irregularly-shaped, branched elastic fibrils, some of which had clubbed terminations (Fig. 3). There was no increase in the amount of collagen present.

The thickness of the pulmonary trunk in each case of the entire series is shown in the Table.

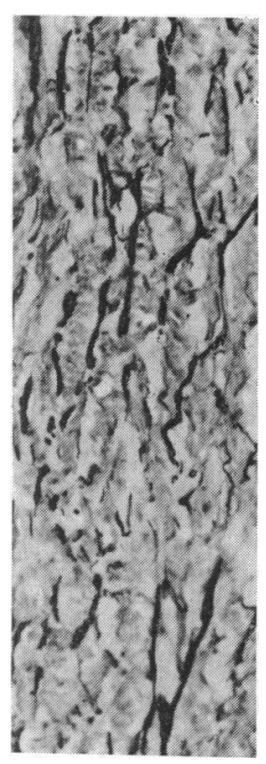

Fig. 3.-Adult pulmonary configuration. Man aged 39 years with mitral stenosis. All the photomicrographs in this paper are transverse sections of pulmonary trunk stained to demonstrate the pattern of the elastic tissue. Lawson modification of the Weigert-Sheridan method for elastic tissue with van Gieson counterstain. $(\times 150$.) 
TABLE

The Thickness of the Fixed PUlmonary Trunk

\begin{tabular}{|c|c|c|c|c|}
\hline Disease* & Sex & $\begin{array}{l}\text { Age } \\
\text { (yr.) }\end{array}$ & $\begin{array}{l}\text { Thickness of } \\
\text { pulmonary trunk } \\
(\mu)\end{array}$ & $\begin{array}{c}\text { Figure } \\
\text { No. }\end{array}$ \\
\hline $\begin{array}{l}\text { MS } \\
\text { MS } \\
\text { MS } \\
\text { MS } \\
\text { MS } \\
\text { MS } \\
\text { MS } \\
\text { MS } \\
\text { MI } \\
\text { FT } \\
\text { FT } \\
\text { FT } \\
\text { FT } \\
\text { FT } \\
\text { FT } \\
\text { IPH (subject D) } \\
\text { IPH ( } \quad \text { M) } \\
\text { VSD ( ", W) } \\
\text { VSD ( ", T) } \\
\text { ASD } \\
\text { ASD }\end{array}$ & $\begin{array}{l}\mathbf{M} \\
\mathbf{F} \\
\mathbf{F} \\
\mathbf{F} \\
\mathbf{F} \\
\mathbf{F} \\
\mathbf{F} \\
\mathbf{F} \\
\mathbf{F} \\
\mathbf{M} \\
\mathbf{M} \\
\mathbf{M} \\
\mathbf{M} \\
\mathbf{M} \\
\mathbf{F} \\
\mathbf{F} \\
\mathbf{F} \\
\mathbf{M} \\
\mathbf{M} \\
\mathbf{F} \\
\mathbf{M}\end{array}$ & $\begin{array}{l}39 \\
47 \\
42 \\
61 \\
52 \\
47 \\
51 \\
51 \\
48 \\
16 \\
47 \\
23 \\
46 \\
16 \\
27 \\
26 \\
15 \\
34 \\
36 \\
41 \\
34\end{array}$ & $\begin{array}{r}1020 \\
1240 \\
1000 \\
930 \\
1320 \\
1190 \\
1090 \\
760 \\
1170 \\
430 \\
390 \\
480 \\
480 \\
280 \\
710 \\
1190 \\
1170 \\
840 \\
830 \\
1000 \\
930\end{array}$ & $\begin{array}{l}3 \\
= \\
= \\
= \\
= \\
\overline{6} \\
7 \\
= \\
= \\
9 \\
10 \\
13 \\
15 \\
\end{array}$ \\
\hline
\end{tabular}

* MS is mitral stenosis; MI is mitral incompetence; FT is Fallot's tetralogy; IPH is idiopathic pulmonary hypertension; VSD is ventricular septal defect; ASD is atrial septal defect.

Fallot's Tetralogy. Figure 4 shows the relation between the extensile force per unit cross-sectional area and the degree of extension observed in this group of subjects. Again, it would be difficult to decide from such a diagram whether the observations were normal or not. The relation between observed and predicted extension presented in Fig. 5 showed a consistent abnormality. The extensibility of the tissue of the pulmonary trunk in these subjects was within normal limits at small degrees of extension but became progressively less than normal with an increasing load.

The elastic tissue of the pulmonary trunk was of "chronic hypotensive configuration" (Heath et al., 1959) which is found typically in patients with diminished pulmonary arterial pressure and flow. The elastic fibrils in these cases were either very thin and sparse (Fig. 6) or had clumped together to form irregularly-shaped isolated masses of elastic tissue separated by much collagen and scanty muscle fibres (Fig. 7).

Idiopathic Pulmonary Hypertension. Figure 8 shows the relation between the observed and predicted values for the degree of extension in these two subjects. It is clear that the tissue of the pulmonary trunk in subject $D$ had a normal extensibility, whereas that of subject $M$ was less extensible than normal. In $\mathrm{D}$ the elastic tissue of the pulmonary trunk was of "adult pulmonary configuration", as found characteristically in patients with acquired pulmonary hypertension. The elastic tissue was in the form of an open network of irregularly-shaped branching fibrils (Fig. 9). In M on the other hand, the elastic tissue of the pulmonary trunk approximated much more closely to the "aortic configuration" which is found when pulmonary arterial hypertension has been present from birth. The elastic fibres were long and more tightly packed. They were uniform and unbranched and ran parallel with one another (Fig. 10). Examination with Mallory's stain failed to reveal any increase in the amount of collagen present.

Ventricular Septal Defect. The relation between the observed and predicted values for the degree of extension in these two subjects is shown in Fig. 11. The tissue of the pulmonary trunk in subject W, who had a small ventricular septal defect (maladie de Roger) and a normal pulmonary 


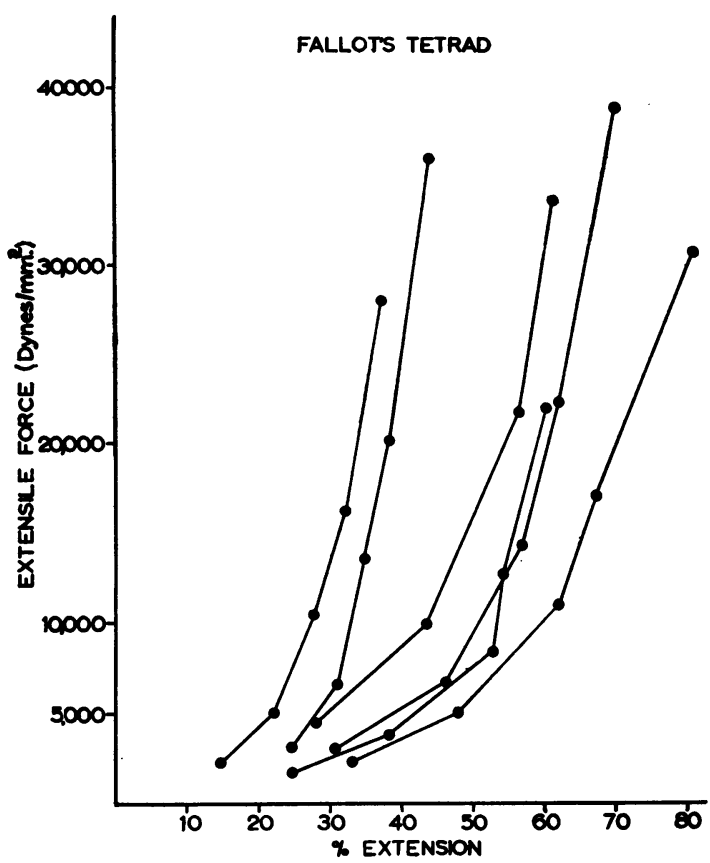

Fig. 4.-The extensibility of the tissue of the pulmonary trunk in subjects with Fallot's tetralogy.

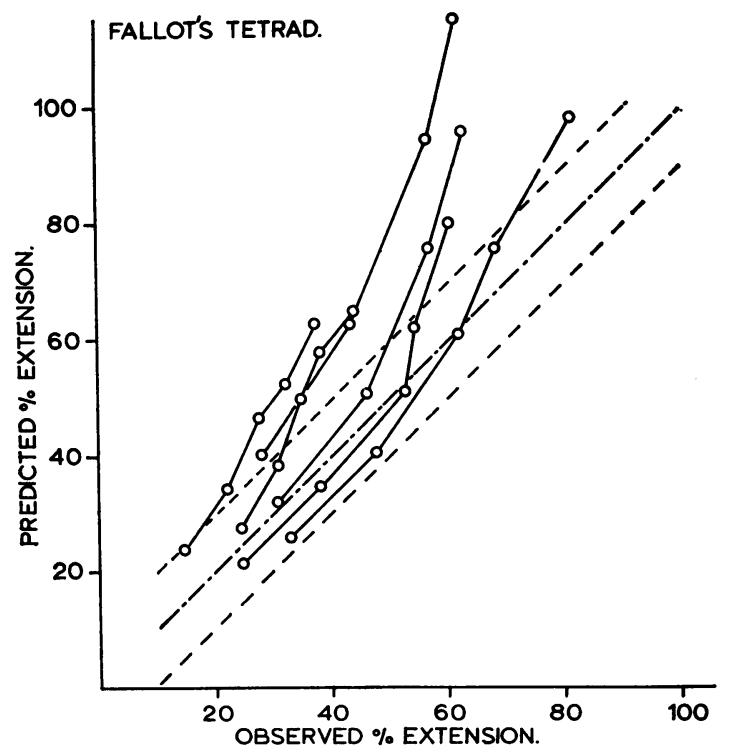

Fig. 5.-The relation between the observed degree of extension and that predicted from equation (1) in subjects with Fallot's tetralogy. The "normal" regression line of equation (2) is shown, together with lines at a distance of twice the standard error of the estimate. Continuous lines join the observations in an individual subject.

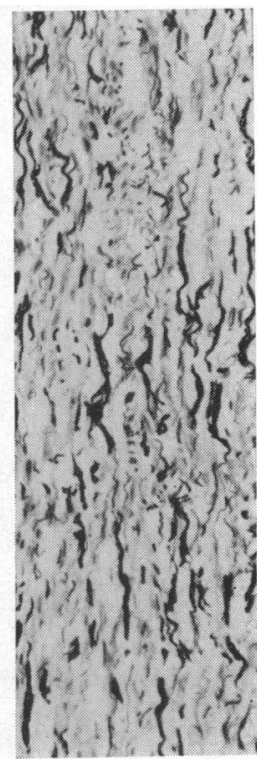

FIG. 6

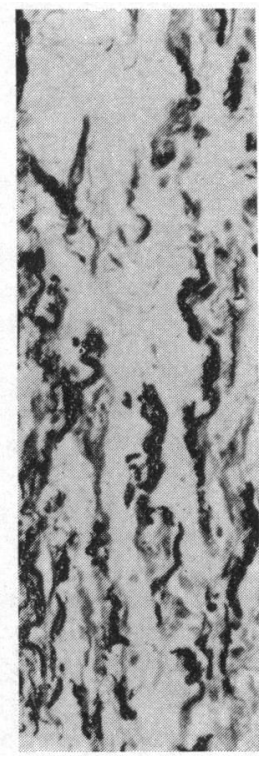

FIG. 7
FIG. 6.-Chronic hypotensive configuration. The elastic fibrils are thin and sparse. Boy aged 16 years with Fallot's tetralogy. $(\times 150$. $)$

Fig. 7.-Chronic hypotensive configuration. The elastic fibrils are thick and separated by much fibrous tissue. Man aged 47 years with Fallot's tetralogy. $(\times 150$.

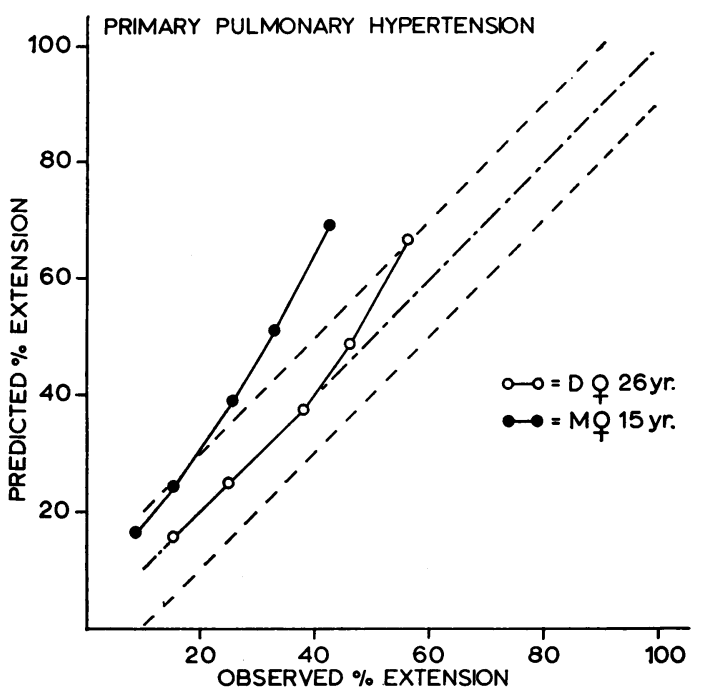

FIG. 8.-The relation between the observed degree of extension and that predicted from equation (1) in two subjects with idiopathic pulmonary hypertension. The "normal" regression line of equation (2) is shown, together with lines at a distance of twice the standard error of the estimate. 


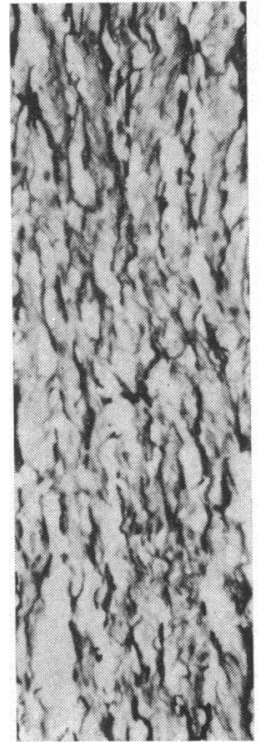

Fig. 9

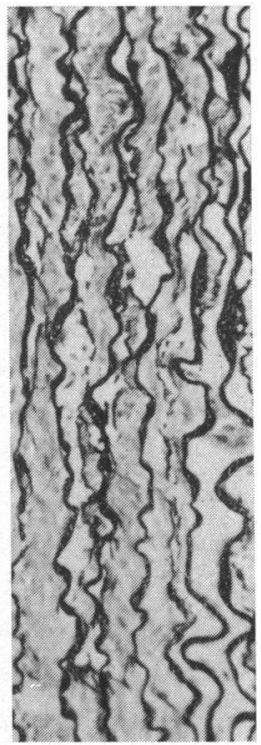

Fig. 10

FIG. 9.-Adult pulmonary configuration. Woman aged 26 years (subject D) with idiopathic pulmonary hypertension. $(\times 150)$.

FIG. 10.-Aortic configuration. Girl aged 15 years (subject $\mathbf{M}$ ) with idiopathic pulmonary hypertension. $(\times 150$.

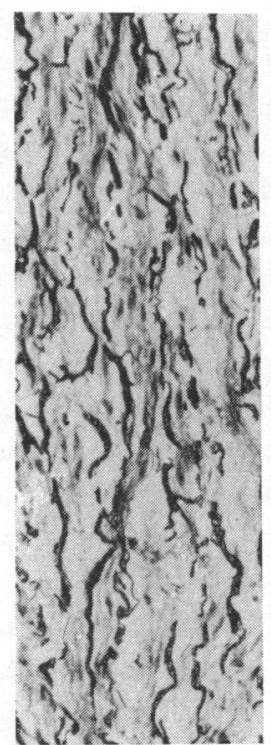

Fig. 12

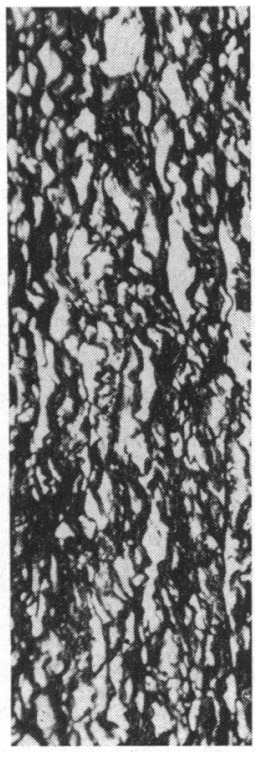

FIG. 13

FIG. 12.-Normal adult pulmonary configuration. Man aged 34 years (subject $W$ ) with a small ventricular septal defect and normal pulmonary arterial pressure. $(\times 150)$

FIG. 13.-Aortic configuration. Man aged 36 years (subject $T$ ) with a large ventricular septal defect and pulmonary hypertension. $(\times 150$.)

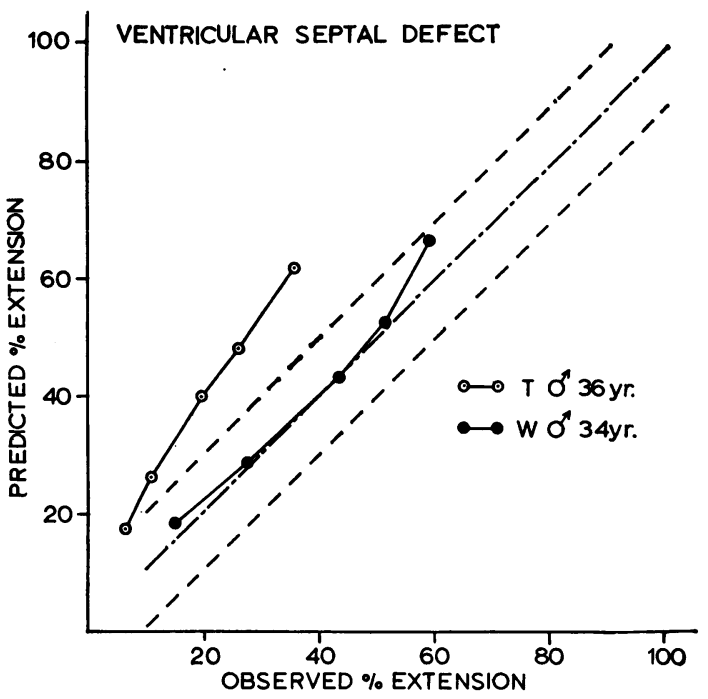

Fig. 11.-The relation between the observed degree of extension and that predicted from equation (1), in two subjects with a ventricular septal defect. The "normal" regression line of equation (2) is shown, together with lines at a distance of twice the standard error of the estimate.

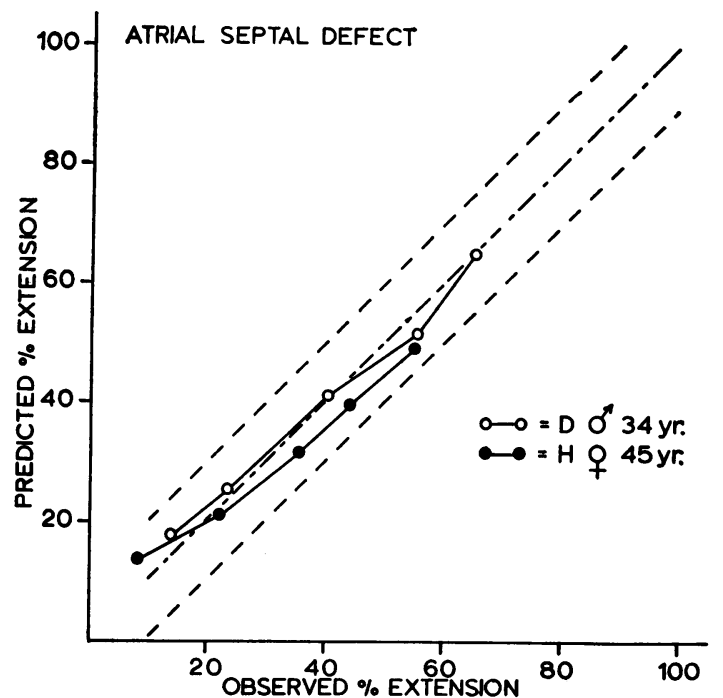

FIG. 14-The relation between the observed degree of extension and that predicted from equation (1) in two subjects with an atrial septal defect. The "normal" regression line of equation (2) is shown, together with lines at a distance of twice the standard error of the estimate. 
arterial pressure, had a normal extensibility. That of subject $T$, who had a large ventricular septal defect and severe pulmonary hypertension, was evidently less extensible than normal. In W the elastic tissue of the pulmonary trunk was of normal adult pulmonary configuration, as might be expected since the pulmonary arterial pressure and flow in this case were normal (Fig. 12). In T the elastic tissue was of aortic pattern which is present when pulmonary arterial hypertension has been present from birth. The elastic fibrils were tightly packed together and ran parallel with one another (Fig. 13). The collagen appeared normal in amount.

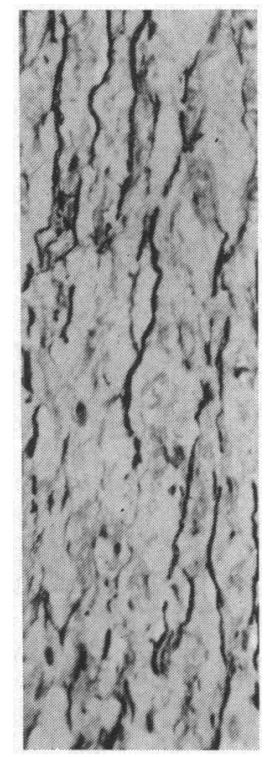

FiG. 15.-Adult pulmonary configuration. Woman aged 44 years with atrial septal defect. $(\times 150$.

Atrial Septal Defect. The relation between the observed and predicted values for the degree of extension in these two subjects is shown in Fig. 14. In both, the tissue of the pulmonary trunk had a normal extensibility. The elastic tissue of the pulmonary trunk was of "adult pulmonary configuration", as found in cases of acquired pulmonary hypertension (Fig. 15). The collagen appeared normal in amount.

\section{Discussion}

All the specimens showed a curved relation between extensile force and the degree of extension. Roach and Burton (1957) have suggested that this is because the elastic fibres have a shorter unstretched length than the collagenous fibres. Thus the initial, more horizontal, portion of the curve is mainly due to the elastic fibres, while the later, more vertical, portion develops as the less extensible collagenous fibres begin to take the strain.

Of the arteries studied, only those from patients with Fallot's tetralogy had an obvious excess of collagen. It may, therefore, be significant that it is in this group that the observed degree of extension was normal in the initial stages but became progressively less than normal with an increasing load.

There were only two arteries with the "aortic" pattern of elastic tissue, one from a subject (T) with a large ventricular septal defect and one from a subject $(\mathrm{M})$ with idiopathic pulmonary hypertension. In both these arteries there was an abnormally dense network of elastic fibres but no obvious excess of collagen. Fig. 8 and 11 suggest that the extensibility is also normal in the initial stages, becoming less than

normal with an increasing load. To some extent, however, this impression derives from the manner of presentation since the standard error is expressed as a constant throughout the range of observations. In fact the first measured degree of extension was already only 35 per cent of that predicted in subject $T$ and 52 per cent of that predicted in subject $M$. In both subjects this percentage increased with an increasing degree of extension. By contrast, the average first measured degree of extension in the specimens from patients with Fallot's tetralogy was 92 per cent of that predicted, while the percentage fell progressively with an increasing degree of extension. Such a difference would be consistent with the presence of an excess of elastic fibres in the two hypertensive subjects and an excess of collagenous fibres in the subjects with Fallot's tetralogy. The number of observations is, however, too small to place too much weight on this interpretation.

In all those arteries where the histological appearance was normal, the extensibility was also normal. This applied even to the subjects with disease of the mitral valve where pulmonary hypertension had been present during life. It may be noted, however, that the extensibility is expressed in terms of unit cross-sectional area, so that the increased thickness of the wall of the pulmonary artery under these circumstances could by itself diminish its extensibility.

We do not know of any similar observations of the extensibility of the pulmonary trunk. There have been some estimations of the volume distensibility of the pulmonary arterial tree. Using the 
"Windkessel" formula, Deuchar and Knebel (1952) estimated that, in two adult patients with a ventricular septal defect and pulmonary hypertension, the coefficients of distensibility were less than normal. Using a similar technique, Lasser and Amram (1956) found that in patients with mitral stenosis the average value for the distensibility was less than the average normal value though there was considerable overlap of the two ranges. The most direct observations of the distensibility of human pulmonary arteries have been made by Meyer and Schollmeyer (1957). These authors measured volume and pressure in the pulmonary trunk and its two main branches after death in patients with mitral stenosis and in patients of the same age who had a normal pulmonary circulation. They found that the volume distensibility was greater in those with mitral stenosis than in the normal group.

The difficulties in relating circumferential extensibility of a blood vessel to its volume distensibility have been discussed by Harris and Heath (1962). The complexity of the relation between these two properties is such that it is not feasible to deduce one from the other without more physical information than is available from the above studies.

\section{SUMMARY}

The extensibility of the tissue of the wall of the pulmonary trunk has been measured in subjects with disease of the mitral valve, Fallot's tetralogy, idiopathic pulmonary hypertension, ventricular septal defect, and atrial septal defect. The measurements have been compared with previously established normal values and the differences from normal evaluated in the light of the histological structure.

Where the microscopical appearance of the pulmonary trunk was normal, its extensibility was also normal. Such subjects included those with disease of the mitral valve or atrial septal defect, one with idiopathic pulmonary hypertension, and one with a small ventricular septal defect.

In one subject with a large ventricular septal defect and in one with idiopathic pulmonary hypertension, the elastic tissue of the pulmonary trunk had the "fœtal" or "aortic" appearance found when pulmonary hypertension has existed from birth. The tissue of the wall of the pulmonary trunk was less extensible than normal in both these subjects.

The specimens from patients with Fallot's tetralogy showed the decrease in elastic tissue and increase in collagen characteristic of this disease. The extensibility of the tissue of the wall of the pulmonary trunk in these cases was normal in the initial stages but became less than normal with an increasing degree of stretch.

\section{REFERENCES}

Deuchar, D. C., and Knebel, R. (1952). The pulmonary and systemic circulations in congenital heart disease. Brit. Heart J., 14, 225.

Harris, P., and Heath, D. (1962). The Human Pulmonary Circulation; its Form and Function in Health and Disease. Livingstone, Edinburgh.

-,$\frac{1}{27,651}$ and Apostolopoulos, A. (1965). The extensibility of the human pulmonary trunk. Brit. Heart J.,

Heath, D., Wood, E. H., DuShane, J. W., and Edwards, J. E. (1959). The structure of the pulmonary trunk at different ages and in cases of pulmonary hypertension and pulmonary stenosis. J. Path. Bact., $77,443$.

Lasser, R. P., and Amram, S. S. (1956). Distensibility of the pulmonary arterial vessels at rest and during exercise in patients with mitral stenosis. Amer. Heart J., 51, 749.

Meyer, W. W., and Schollmeyer, P. (1957). Die Volumendehnbarkeit und die Druck-Umfang-Beziehungen des Lungenschlagader-Windkessels in Abhangigkeit vom Alter und pulmonalen Hochdruck. Klin. Wschr., 35, 1070 .

Roach, M. R., and Burton, A. C. (1957). The reason for the shape of the distensibility curves of arteries. Canad.J. Biochem., 35, 681 . 